\title{
SCIDOC
}

International Journal of Computational \& Neural Engineering (IJCNE)

ISSN:2572-7389

\section{Monetary Dependency of Women in Pakistan and Domestic Violence: An Underreported Socio-psychological Crisis}

Ali Khan ${ }^{1 *}$, Sidra Mamsa ${ }^{2}$, Maira Saleem³, Rabia Saleem ${ }^{4}$

${ }^{1}$ Medical Graduate, Dow University of Health and Sciences, Karachi, Pakistan.

${ }^{2}$ American University of Integrative Sciences, St Michael Barbados, USA.

${ }^{3}$ Medical Officer, Jinnah Postgraduate Medical Center, Karachi, Pakistan.

${ }^{4}$ MedicalGraduate, Jinnah Medical and Dental College, Karachi, Pakistan.

Abstract

Unfortunately, domestic/spouse abuse of women in Pakistan is a common social problem. As there are many factors that contribute directly or indirectly to domestic violence, economical dependency of females is a major influencer. We've conducted a brief search to comment on this essential socio-psychological issue which is negatively impacting physical and mental health of feminine population in Pakistan. Unemployment of Pakistani women due to inadequate professional education is a prominent reason behind financial instability.

Keywords: Domestic Violence; Violence Exposure; PTSD; Sexual Assault; Mental Health and Violence.

\section{Review of Literature}

Domestic violence is an illegal and socially unacceptable issue which has been prevailing in Pakistan for some decades now. Major hindrance in the assessment of actual burden of this sociopsychological problem is the under-reporting ofcases.Insufficient reporting can be due to fear of financial instability, fear of losing her children custody, sabotaging family honor, fear of facing vengeance from their partner or fear of being stigmatized as 'Bad Wife'. It is a cultural norm in Pakistan that whatever happen between married couples is considered as 'Personal matter' and no outsider has a right to intrude their privacy, even if it is an act that is considered as unlawful according to both the constitution of Pakistan as well as Islamic teachings.[1] Traditionally in Pakistan, male are usually the 'Bread Earner' and female are the 'Care provider' of family. Therefore, majority of the female are unemployed and financially dependent on their male counterpart. This monetary dependency prevent them from opting for social help [2].

Published medical literature suggest that economically independent females are less likely to be victimized by spouse abuse as compared to dependent females. A study by Chatha SA et al on
Pakistani population suggested that financial stability and literacy of both husband and wife contribute to lower incidence of domestic abuse as compared to the illiterate and financially handicapped couples [3]. Another similar study on domestic abuse in Pakistan reported the major perceived risk factors for intra-marital conflicts. Economical limitations (60\% of the study population) contributed the most which led to increase incidence of intra-marital abuse [4]. One of the core reason behind this financial instability of Pakistani female is unemployment which roots from insufficient professional qualification, adjustment to marriage,cultural restraints and non-facilitative social structure. According to a study published in 2013, percentage of females who enrolled for a university education were significantly lower than male candidates [5]. Therefore, the literacy rate (criteria of being literate is to know how to read and write) of women in $\mathrm{Pa}$ kistan is only $36 \%$. In comparison to male employment rate which is about $77.8 \%$ in urban regions, female employment rate $(22.2 \%)$ is significantly inadequate [6].

Cultural road blocks are also considered as major constraints. Women are often perceived as a fragile entity who cannot take care of herself or make life altering decisions for her own sake. Primary purpose of educating girls in Pakistan is the intellectual

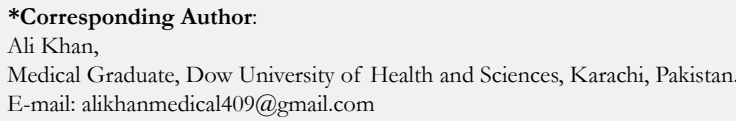

Citation: Ali Khan, Sidra Mamsa, Maira Saleem, Rabia Saleem. Monetary Dependency of Women in Pakistan and Domestic Violence: An Underreported Socio-psychological Crisis. Int J Comput Neural Eng. 2021;7(1):117-118. doi: http://dx.doi.org/10.19070/2572-7389-2100014

Copyright: Ali Khan ${ }^{\circ} 2021$. This is an open-access article distributed under the terms of the Creative Commons Attribution License, which permits unrestricted use, distribution and reproduction in any medium, provided the original author and source are credited. 
cultivation of young girls to become an educated mother rather than an encouragement to pursue a professional career. Even if women are allowed to pursue a career, they are forced to choose a less challenging job which is not the case for Pakistani men who are free with their choices [7]. Other factors that can contribute in female dependency are inequality in pay, discontinuity in job due to maternity leaves, unshared responsibility of taking care a dependent child and uncooperative in-laws and spouse.

Women who are subjected to spouse violence have an increased susceptibility to develop mental health issues like post-traumatic stress disorder (PTSD), panic disorder, depressive symptoms, anxiety disorders or an augmented suicidal tendency. Any obvious disfigurement as a result of physical violence such as burn marks, scars, skeletal deformities or an amputated body parts such as nose or fingers can also negatively impact on mental health in a long run [8]. According to a cross-sectional survey conducted on 759 married women in Karachi, suicidal ideation (58.8\%) was the most prevalent psychological condition in victims of abuse followed by feeling of worthlessness (42.3\%). Association of suicidality had the most strongest association with sexual abuse $(75.8 \%)$ followed by physical violence $(74.1 \%)$ and psychological abuse $(65.3 \%)$ [6]. A 5-year survey conducted in Karachi was suggestive about the prevailing number of women who are seeking psychotherapy. Out of all women in study population, $72 \%$ were married and relate their distressing symptoms to conflicts with husband and his family [9]. This increasing prevalence of 'distress' is concerning and demand a serious action by regulating authorities against domestic violence.

According to a study by Ali TS et al, classic trio of levels of prevention can be implemented to minimize the abuse of Pakistani women.Awareness campaign on women rights and legal consequences of practicing domestic violence should be conducted as a primary level of prevention. Hospitals, community centers, neighbors or even a stranger pedestrian can participate in secondary prevention by reporting a suspected or witnessed spouse vio- lence to local law enforcing agencies. Development of protective services system for victims of domestic violence and physical or mental rehabilitation can contribute to tertiary prevention [10].

\section{Conclusion}

Education of girls not solely for the purpose of 'educating' them, but to make them qualified enough to be able to do an independent professional paid job is essential in minimizing domestic abuse in Pakistan because financial dependency of women is an independent major contributor in the growth of domestic abuse. It's important to empower Pakistani women to alleviate the severity of this socio-psychological crisis.

\section{References}

[1]. Ali TS, Asad N, Mogren I, Krantz G. Intimate partner violence in urban Pakistan: prevalence, frequency, and risk factors. Int J Womens Health. 2011; 16(3): 105-15. PMID: 21573146.

[2]. Shaikh MA. Is domestic violence endemic in Pakistan: perspective from $\mathrm{Pa}$ kistani wives. Pakistan Journal of Medical Sciences. 2003;19(1): 23-8.

[3]. Chatha SA, K Ahmad, KS Sheikh. Socio-economic status and domestic violence: a study on married women in urban Lahore, Pakistan. South Asian Studies. 2020; 29(1): 229.

[4]. Fikree FF, Bhatti LI. Domestic violence and health of Pakistani women. Int J Gynaecol Obstet. 1999; 65(2):195-201. PMID: 10405066.

[5]. Batool SQ, Sajid MA, Shaheen I. Gender and higher education in Pakistan. International Journal of Gender and Women's Studies. 2013;1(1):15-28.

[6]. Ali TS, Mogren I, Krantz G. Intimate partner violence and mental health effects: a population-based study among married women in Karachi, Pakistan. Int J Behav Med. 2013; 20(1):131-9. PMID: 22037921.

[7]. Shabib-ul-Hasan S, Mustafa S. Education to profession! Challenges of being women in Pakistan. AI \& society. 2014; 29(1):131-6.

[8]. Shaikh MA. Domestic violence against women--perspective from Pakistan. J Pak Med Assoc. 2000; 50(9):312-4. PMID: 11043022.

[9]. Niaz U. Women's mental health in Pakistan. World Psychiatry. 2004 Feb;3(1):60-2. PMID: 16633458.

[10]. Ali TS, Khan N. Strategies and recommendations for prevention and control of domestic violence against women in Pakistan. J Pak Med Assoc. 2007; 57(1): 27-32. PMID: 17319416. 